CAHIERs de Recherche/ Working PAPERS

03-01

Gini Decomposition and

Gini Income Elasticity

Under Income Variability

\author{
Paul MAKDISSI \\ et \\ Quentin WODON
}

UNIVERSITÉ DE SHERBROOKE

Faculté des lettres et sciences humaines

Département d'économique 


\title{
Gini Decomposition and Gini Income Elasticity Under Income Variability
}

\author{
Paul Makdissi* Quentin Wodon ${ }^{\dagger}$
}

April 2003

\begin{abstract}
The Gini income elasticity has been used to assess the impact of marginal proportional changes in income from a given source on inequality in total income. This note extends the methodology to take into account income variability.
\end{abstract}

Keywords: Inequality, Gini Decomposition, Uncertainty. JEL Codes: D31, I30.

* Département d'économique and CEREF, Université de Sherbrooke, 2500, boulevard de l'Université, Sherbrooke, Québec, Canada, J1K 2R1; Email: paul.makdissi@usherbrooke.ca.

† AFTPM, World Bank, 1818 H Street, NW, Washington, DC 20433, USA, Email: qwodon@worldbank.org. 


\section{Introduction}

The Gini Income Elasticity (GIE hereafter) is a parameter that measures the impact on the (extended) Gini index of income inequality of a marginal proportional change in an income source (e.g., Lerman and Yitzhaki 1985). Estimates of the GIE have been used, among others, for assessing the impact on inequality of increases in outlays for social programs (e.g., Lerman and Yitzhaki 1994, Wodon and Yitzhaki 2002). However, while an increase in funding for programs such as unemployment benefits may reduce inequality in mean income, it may also reduce income variability or risk, and this is not taken into account in the traditional decomposition of the Gini index. In this note, we show that under income variability (assuming that the observations represent a draw from states of nature), an income source has three GIEs corresponding to the three ways in which the income source affects the certainty equivalent income: a) the mean income from the source over time, b) the variability in income from the source, and c) the correlation over time between income from the source and income from other sources. The total impact on inequality of a marginal change in income from the source is then a function of these three GIEs.

\section{Method}

Consider a situation where total income is the sum of income from $J$ sources. The standard decomposition of the Gini index is

$$
G=\sum_{j=1}^{J} \underbrace{\left[\operatorname{COV}\left(y_{j}, F\right) / \operatorname{COV}\left(y_{j}, F_{j}\right)\right]}_{R_{j}} \underbrace{\left[2 \operatorname{COV}\left(y_{j}, F_{j}\right) / m_{j}\right]}_{G_{j}} \underbrace{\left[m_{j} / m\right]}_{S_{j}}
$$


where $y_{j}$ is income from source $j, F$ is the rank of the individual (or household) in the distribution of total income, $F_{j}$ is the rank in the distribution of income from source $j, m_{j}$ is the source's mean income, and $m$ is mean total income. In equation (1), $R_{j}$ is the Gini correlation between total income and income from source $j, G_{j}$ is the Gini of source $j$, and $S_{j}$ is the source's share of total income. It can be shown that the impact on inequality of a marginal proportional change in income from source $j$ is such that

$$
\frac{\frac{\partial G}{\partial e}}{G}=S_{j}\left(\eta_{j}-1\right)
$$

where the GIE, denoted by $\eta_{j}$, is defined as

$$
\eta_{j}=\frac{R_{j} G_{j}}{G} .
$$

A GIE higher (lower) than one denotes an income sources that is inequality increasing (decreasing) at the margin.

In this note, we extend this decomposition and the concept of the GIE to a context in which individuals are subject to income variability over time. Our strategy consists in considering the income variable $y$ in (1) as the certainty equivalent income of the individual, and to apply the decomposition to that certainty equivalent. If the actual income for individual $i$ is denoted by $x_{i}-$ this is a random variable with density function $g_{i}(\cdot)$, the certainty equivalent income $y_{i}$ is defined through

$$
u\left(y_{i}\right)=\int_{0}^{\infty} u(x) g_{i}(x) d x .
$$

where $u(\cdot)$ does not represents the Bernoulli utility function of the individual, but rather a social judgement on the impact of income variability on welfare. Denote by $\mu_{i}$ the individual's mean income over time. The cost of variability, $c\left(g_{i} ; u\right)$, is defined by

$$
u\left(\mu_{i}-c\left(g_{i} ; u\right)\right)=\int_{0}^{\infty} u(x) g_{i}(x) d x,
$$


Using a Taylor expansion, an approximation of this cost is

$$
c\left(g_{i} ; u\right) \simeq 0.5 \bar{r}_{a}^{i} \sigma_{i}^{2},
$$

where $\bar{r}_{a}^{i}$ is the Arrow-Pratt absolute risk aversion index measured at $\mu_{i}$, and $\sigma_{i}^{2}$ is the variance of the individual's income. In this note, for simplicity, we assume a constant absolute risk aversion (denoted by $\rho$ ), so that

$$
y_{i}=\mu_{i}-0.5 \rho \sigma_{i}^{2} .
$$

Return now to the fact that there are $J$ sources of income with means over time $\mu_{i j}$ for individual $i$ so that

$$
\mu_{i}=\sum_{j=1}^{J} \mu_{i j}
$$

and

$$
\sigma_{i}^{2}=\sum_{j=1}^{J} \sigma_{i j}^{2}+2 \sum_{j=1}^{J} \sum_{k=j+1}^{J} \operatorname{COV}\left(x_{i j}, x_{i k}\right),
$$

where $\operatorname{COV}(a, b)$ is the covariance between $a$ and $b$. We have

$$
\sum_{j=1}^{J} \sum_{k=j+1}^{J} \operatorname{COV}\left(x_{i j}, x_{i k}\right)=0.5 \sum_{j=1}^{J} \operatorname{COV}\left(x_{i j}, x_{i j}^{-}\right) .
$$

where $x_{i j}^{-}=x_{i}-x_{i j}$. Using (8), (9) and (10), (7) may be rewritten as

$$
y_{i}=\sum_{j=1}^{J}\left\{\mu_{i j}+\phi_{i j}+\xi_{i j}\right\}
$$

where $\phi_{i j}=-0.5 \rho \sigma_{i j}^{2}$ is the cost of the income variability of source $j$, and $\xi_{i j}=-0.5 \rho \operatorname{COV}\left(x_{i j}, x_{i j}^{-}\right)$is the cost (or benefit) due to the covariance between source $j$ and other income sources. If we denote by $m_{j}^{\mu}, m_{j}^{\phi}$ and $m_{j}^{\xi}$ the mean values over the population as a whole of $\mu_{i j}, \phi_{i j}$, and $\xi_{i j}$, and as 
before by $m$ the mean value of $y_{i}$, applying (1) to (11) yields for each income source three components in the decomposition of the Gini

$$
\begin{aligned}
G= & \sum_{j=1}^{J}\left\{\left[\operatorname{COV}\left(\mu_{j}, F\right) / \operatorname{COV}\left(\mu_{j}, F_{j}^{\mu}\right)\right]\left[2 \operatorname{COV}\left(\mu_{j}, F_{j}^{\mu}\right) / m_{j}^{\mu}\right]\left[m_{j}^{\mu} / m\right]\right. \\
+ & {\left[\operatorname{COV}\left(\phi_{j}, F\right) / \operatorname{COV}\left(\phi_{j}, F_{j}^{\phi}\right)\right]\left[2 \operatorname{COV}\left(\phi_{j}, F_{j}^{\phi}\right) / m_{j}^{\phi}\right]\left[m_{j}^{\phi} / m\right] } \\
+ & {\left.\left[\operatorname{COV}\left(\xi_{j}, F\right) / \operatorname{COV}\left(\xi_{j}, F_{j}^{\xi}\right)\right]\left[2 \operatorname{COV}\left(\xi_{j}, F_{j}^{\xi}\right) / m_{j}^{\xi}\right]\left[m_{j}^{\xi} / m\right]\right\}, }
\end{aligned}
$$

Using a notation similar to (1), this yields

$$
G=\sum_{j=1}^{J}\left\{R_{j}^{\mu} G_{j}^{\mu} S_{j}^{\mu}+R_{j}^{\phi} G_{j}^{\phi} S_{j}^{\phi}+R_{j}^{\xi} G_{j}^{\xi} S_{j}^{\xi}\right\} .
$$

Consider now a small proportional change in an income source by a factor of $e$, such that $y_{i k}(e)=(1+e) \mu_{i k}+(1+e)^{2} \phi_{i k}+(1+e) \xi_{i k}$. It is shown in appendix that

$$
\frac{\partial G}{\partial e}=S_{j}^{\mu}\left(R_{j}^{\mu} G_{j}^{\mu}-G\right)+2 S_{j}^{\phi}\left(R_{j}^{\phi} G_{j}^{\phi}-G\right)+S_{j}^{\xi}\left(R_{j}^{\xi} G_{j}^{\xi}-G\right) .
$$

Dividing by $G$, we get

$$
\frac{\frac{\partial G}{\partial e}}{G}=S_{j}^{\mu}\left(\eta_{j}^{\mu}-1\right)+2 S_{j}^{\phi}\left(\eta_{j}^{\phi}-1\right)+S_{j}^{\xi}\left(\eta_{j}^{\xi}-1\right),
$$

where $\eta_{j}^{\mu}=\frac{R_{j}^{\mu} G_{j}^{\mu}}{G}, \quad \eta_{j}^{\phi}=\frac{R_{j}^{\phi} G_{j}^{\phi}}{G}, \quad$ and $\quad \eta_{j}^{\xi}=\frac{R_{j}^{\xi} G_{j}^{\xi}}{G}$.

With cross-section data, since we do not observe income variability, only the first term on the righ hand side of (14) appears, so that whether an income source increases or decreases inequality at the margin is solely determined by whether the GIE $\eta_{j}^{\mu}$ is above or below one. In a panel setting, we have instead three sources of impact at the margin, and thereby three GIEs related to a) the mean income from the source over time, b) the variability of the source, and c) the correlation between the source and other sources over 
time. For example, a source such as unemployment benefits may reduce inequality in certainty equivalent income at the margin not only through targeting individuals with comparatively low mean income, but also through reducing income variability for these individuals, with this beneficial effect appearing through the third GIE in (14).

One last point: to introduce flexibility in the measurement of inequality, we may use the extended Gini coefficient (Yitzhaki, 1983), in which case the weights placed on various parts of the distribution of the certainty equivalent income will depend on a parameter $v$. A value of 2 yields the standard Gini. A higher (lower) value places more (less) weights on lower parts of the distribution. All the results will remain valid. We will have

$$
G(v)=\sum_{j=1}^{J}\left\{R_{j}^{\mu}(v) G_{j}^{\mu}(v) S_{j}^{\mu}+R_{j}^{\phi}(v) G_{j}^{\phi}(v) S_{j}^{\phi}+R_{j}^{\xi}(v) G_{j}^{\xi}(v) S_{j}^{\xi}\right\},
$$

where

$$
R_{j}^{\mu}(v)=\frac{\operatorname{COV}\left[\mu_{j},(1-F)^{v-1}\right]}{\operatorname{COV}\left[\mu_{j},\left(1-F_{j}^{\mu}\right)^{v-1}\right]}
$$

and

$$
G_{j}^{\mu}(v)=-v \frac{C O V\left[\mu_{j},\left(1-F_{j}^{\mu}\right)^{v-1}\right]}{m_{j}^{\mu}} .
$$

$R_{j}^{\phi}(v), G_{j}^{\phi}(v), R_{j}^{\xi}(v)$, and $G_{j}^{\xi}(v)$ are defined analogously. Following a small proportional change in income from a source, we will have

$$
\begin{gathered}
\frac{\frac{\partial G(v)}{\partial e}}{G(v)}=S_{j}^{\mu}\left(\eta_{j}^{\mu}(v)-1\right)+2 S_{j}^{\phi}\left(\eta_{j}^{\phi}(v)-1\right)+S_{j}^{\xi}\left(\eta_{j}^{\xi}(v)-1\right) \\
\text { where } \eta_{j}^{\mu}(v)=\frac{R_{j}^{\mu}(v) G_{j}^{\mu}(v)}{G(v)}, \quad \eta_{j}^{\phi}(v)=\frac{R_{j}^{\phi}(v) G_{j}^{\phi}(v)}{G(v)}, \text { and } \eta_{j}^{\xi}(v)=\frac{R_{j}^{\xi}(v) G_{j}^{\xi}(v)}{G(v)} .
\end{gathered}
$$




\section{Conclusion}

Most of the work for assessing the impact of public transfers on inequality is based on cross-sectional data. Yet many transfers are designed not only to reach the poor, but also to offset the impact of income variability on welfare. In this note, we have extended the source decomposition of the Gini index of inequality to show how to evaluate the impact at the margin on inequality of a proportional increase in program outlays under income variability. When considering inequality in certainty equivalent income, each income source can be said to have three Gini Income Elasticities corresponding to the three terms appearing in the Taylor approximation of the individual's cetainty equivalent income, namely the mean income from the source, the variability

of the source over time, and the covariance between the source and other income sources over time.

\section{References}

[1] Lerman, R.I. and S. Yitzhaki (1985), Income Inequalitty Effects by Income Sources: A New Approach and Applications to the United States, Review of Economics and Statistics, 67: 151-156.

[2] Lerman, R.I. and S. Yitzhaki (1994), The Effect of Marginal Changes in Income Sources on U.S. Income Inequality, Public Finance Quarterly, 22: 403-417.

[3] Stark, O., J. E. Taylor and S. Yitzhaki (1986), Remittances and Inequality, Economic Journal, 96, 722-740. 
[4] Wodon, Q., and S. Yitzhaki (2002), Evaluating the Impact of Government Programs on Social Welfare: The Role of Targeting and the Allocation Rules Among Program Beneficiaries, Public Finance Review, 30: 102-23.

[5] Yitzhaki, S. (1983), On an Extension of the Gini Inequality Index, International Economic Review, 24, 617-628.

\section{A Proof of (13)}

This proof follows closely Stark et al. (1986). We first note that after a marginal proportional change in income from source $k$

$$
S_{j}^{\mu}(e)=\left\{\begin{array}{cl}
\frac{m_{j}^{\mu}}{\sum_{l=1}^{J}\left\{m_{l}^{\mu}+m_{l}^{\phi}+m_{l}^{\xi}\right\}+e\left\{m_{k}^{\mu}+m_{k}^{\phi}+m_{k}^{\xi}\right\}+e(1+e) m_{k}^{\phi}} & \text { for } j \neq k \\
\frac{(1+e) m_{k}^{\mu}}{\sum_{l=1}^{J}\left\{m_{l}^{\mu}+m_{l}^{\phi}+m_{l}^{\xi}\right\}+e\left\{m_{k}^{\mu}+m_{k}^{\phi}+m_{k}^{\xi}\right\}+e(1+e) m_{k}^{\phi}} & \text { for } j=k
\end{array} .\right.
$$

$S_{j}^{\xi}(e)$ is defined analogously. However,

$$
S_{j}^{\phi}(e)=\left\{\begin{array}{cl}
\frac{m_{j}^{\mu}}{\sum_{l=1}^{J}\left\{m_{l}^{\mu}+m_{l}^{\phi}+m_{l}^{\xi}\right\}+e\left\{m_{k}^{\mu}+m_{k}^{\phi}+m_{k}^{\xi}\right\}+e(1+e) m_{k}^{\phi}} & \text { for } j \neq k \\
\frac{(1+e)^{2} m_{k}^{\mu}}{\sum_{l=1}^{J}\left\{m_{l}^{\mu}+m_{l}^{\phi}+m_{l}^{\xi}\right\}+e\left\{m_{k}^{\mu}+m_{k}^{\phi}+m_{k}^{\xi}\right\}+e(1+e) m_{k}^{\phi}} & \text { for } j=k
\end{array} .\right.
$$

If the change in income from source $k$ is suffciently small, all ranks are preserved. As in Stark et al. (1986), this implies that

$$
\begin{aligned}
G(e)-G= & \sum_{j=1}^{J}\left\{R_{j}^{\mu} G_{j}^{\mu} S_{j}^{\mu}(e)+R_{j}^{\phi} G_{j}^{\phi} S_{j}^{\phi}(e)+R_{j}^{\xi} G_{j}^{\xi} S_{j}^{\xi}(e)\right\} \\
& -\sum_{j=1}^{J}\left\{R_{j}^{\mu} G_{j}^{\mu} S_{j}^{\mu}+R_{j}^{\phi} G_{j}^{\phi} S_{j}^{\phi}+R_{j}^{\xi} G_{j}^{\xi} S_{j}^{\xi}\right\},
\end{aligned}
$$




$$
\begin{aligned}
G(e)-G= & \sum_{j=1}^{J} R_{j}^{\mu} G_{j}^{\mu}\left[S_{j}^{\mu}(e)-S_{j}^{\mu}\right] \\
& +\sum_{j=1}^{J} R_{j}^{\phi} G_{j}^{\phi}\left[S_{j}^{\phi}(e)-S_{j}^{\phi}\right] \\
& +\sum_{j=1}^{J} R_{j}^{\xi} G_{j}^{\xi}\left[S_{j}^{\xi}(e)-S_{j}^{\xi}\right] .
\end{aligned}
$$

From (19) and (20), we can compute for $j \neq k$,

$$
\begin{aligned}
& S_{j}^{\mu}(e)-S_{j}^{\mu}= \frac{m_{j}^{\mu}}{\sum_{l=1}^{J}\left\{m_{l}^{\mu}+m_{l}^{\phi}+m_{l}^{\xi}\right\}+e\left\{m_{k}^{\mu}+m_{k}^{\phi}+m_{k}^{\xi}\right\}+e(1+e) m_{k}^{\phi}} \\
&-\frac{m_{j}^{\mu}}{\sum_{l=1}^{J}\left\{m_{l}^{\mu}+m_{l}^{\phi}+m_{l}^{\xi}\right\}}, \\
& S_{j}^{\mu}(e)-S_{j}^{\mu}=\frac{-e S_{j}^{\mu}\left\{S_{k}^{\mu}+S_{k}^{\phi}+S_{k}^{\xi}+e(1+e) S_{k}^{\phi}\right\}}{1+e\left(S_{k}^{\mu}+S_{k}^{\phi}+S_{k}^{\xi}\right)+e(1+e) S_{k}^{\phi}} .
\end{aligned}
$$

$S_{j}^{\phi}(e)-S_{j}^{\phi}$ and $S_{j}^{\xi}(e)-S_{j}^{\xi}$ have analogous forms. For $j=k$,

$$
\begin{aligned}
S_{k}^{\mu}(e)-S_{k}^{\mu}= & \frac{(1+e) m_{k}^{\mu}}{\sum_{l=1}^{J}\left\{m_{l}^{\mu}+m_{l}^{\phi}+m_{l}^{\xi}\right\}+e\left\{m_{k}^{\mu}+m_{k}^{\phi}+m_{k}^{\xi}\right\}+e(1+e) m_{k}^{\phi}} \\
& -\frac{m_{k}^{\mu}}{\sum_{l=1}^{J}\left\{m_{l}^{\mu}+m_{l}^{\phi}+m_{l}^{\xi}\right\}}, \\
S_{k}^{\mu}(e)-S_{k}^{\mu}= & \frac{e S_{k}^{\mu}-e S_{k}^{\mu}\left\{S_{k}^{\mu}+S_{k}^{\phi}+S_{k}^{\xi}+e(1+e) S_{k}^{\phi}\right\}}{1+e\left(S_{k}^{\mu}+S_{k}^{\phi}+S_{k}^{\xi}\right)+e(1+e) S_{k}^{\phi}} .
\end{aligned}
$$

$S_{j}^{\xi}(e)-S_{j}^{\xi}$ has an analogous form. However

$$
\begin{aligned}
S_{k}^{\phi}(e)-S_{k}^{\phi}= & \frac{(1+e)^{2} m_{k}^{\phi}}{\sum_{l=1}^{J}\left\{m_{l}^{\mu}+m_{l}^{\phi}+m_{l}^{\xi}\right\}+e\left\{m_{k}^{\mu}+m_{k}^{\phi}+m_{k}^{\xi}\right\}+e(1+e) m_{k}^{\phi}} \\
& -\frac{m_{k}^{\mu}}{\sum_{l=1}^{J}\left\{m_{l}^{\mu}+m_{l}^{\phi}+m_{l}^{\xi}\right\}}
\end{aligned}
$$




$$
S_{k}^{\phi}(e)-S_{k}^{\phi}=\frac{e S_{k}^{\phi}+e(1+e) S_{k}^{\phi}-e S_{k}^{\phi}\left\{S_{k}^{\mu}+S_{k}^{\phi}+S_{k}^{\xi}+e(1+e) S_{k}^{\phi}\right\}}{1+e\left(S_{k}^{\mu}+S_{k}^{\phi}+S_{k}^{\xi}\right)+e(1+e) S_{k}^{\phi}} .
$$

Using (24), (23), (22) and (21), we get

$$
\begin{aligned}
G(e)-G= & \sum_{j=1}^{J} \frac{-e S_{j}^{\mu}\left\{S_{k}^{\mu}+S_{k}^{\phi}+S_{k}^{\xi}+(1+e) S_{k}^{\phi}\right\}}{1+e\left(S_{k}^{\mu}+S_{k}^{\phi}+S_{k}^{\xi}\right)+e(1+e) S_{k}^{\phi}} R_{j}^{\mu} G_{j}^{\mu} \\
& +\frac{e S_{k}^{\mu}}{1+e\left(S_{k}^{\mu}+S_{k}^{\phi}+S_{k}^{\xi}\right)+e(1+e) S_{k}^{\phi}} R_{k}^{\mu} G_{k}^{\mu} \\
& +\sum_{j=1}^{J} \frac{-e S_{j}^{\phi}\left\{S_{k}^{\mu}+S_{k}^{\phi}+S_{k}^{\xi}+(1+e) S_{k}^{\phi}\right\}}{1+e\left(S_{k}^{\mu}+S_{k}^{\phi}+S_{k}^{\xi}\right)+e(1+e) S_{k}^{\phi}} R_{j}^{\phi} G_{j}^{\phi} \\
& +\frac{e(2+e) S_{k}^{\phi}}{1+e\left(S_{k}^{\mu}+S_{k}^{\phi}+S_{k}^{\xi}\right)+e(1+e) S_{k}^{\phi}} R_{k}^{\phi} G_{k}^{\phi} \\
& +\sum_{j=1}^{J} \frac{-e S_{j}^{\xi}\left\{S_{k}^{\mu}+S_{k}^{\phi}+S_{k}^{\xi}+(1+e) S_{k}^{\phi}\right\}}{1+e\left(S_{k}^{\mu}+S_{k}^{\phi}+S_{k}^{\xi}\right)+e(1+e) S_{k}^{\phi}} R_{j}^{\xi} G_{j}^{\xi} \\
& +\frac{e_{k}^{\xi}}{1+e\left(S_{k}^{\mu}+S_{k}^{\phi}+S_{k}^{\xi}\right)+e(1+e) S_{k}^{\phi}} R_{k}^{\xi} G_{k}^{\xi} .
\end{aligned}
$$


Taking the limit, we get

$$
\begin{aligned}
\lim _{e \rightarrow \mathbf{0}} \frac{G(e)-G}{e}= & -\lim _{e \rightarrow \mathbf{0}}\left\{S_{k}^{\mu}+S_{k}^{\phi}+S_{k}^{\xi}+(1+e) S_{k}^{\phi}\right\} \sum_{j=1}^{J} \frac{S_{j}^{\mu}}{1+e\left(S_{k}^{\mu}+S_{k}^{\phi}+S_{k}^{\xi}\right)} R_{j}^{\mu} G_{j}^{\mu} \\
& +\lim _{e \rightarrow \mathbf{0}} \frac{S_{k}^{\mu}}{1+e\left(S_{k}^{\mu}+S_{k}^{\phi}+S_{k}^{\xi}\right)+e(1+e) S_{k}^{\phi}} R_{k}^{\mu} G_{k}^{\mu} \\
& -\lim _{e \rightarrow \mathbf{0}}\left\{S_{k}^{\mu}+S_{k}^{\phi}+S_{k}^{\xi}+(1+e) S_{k}^{\phi}\right\} \sum_{j=1}^{J} \frac{S_{j}^{\phi}}{1+e\left(S_{k}^{\mu}+S_{k}^{\phi}+S_{k}^{\xi}\right)} R_{j}^{\phi} G_{j}^{\phi} \\
& +\lim _{e \rightarrow \mathbf{0}} \frac{\left(2+S_{k}^{\phi}\right.}{1+e\left(S_{k}^{\mu}+S_{k}^{\phi}+S_{k}^{\xi}\right)+e(1+e) S_{k}^{\phi}} R_{k}^{\phi} G_{k}^{\phi} \\
& -\lim _{e \rightarrow \mathbf{0}}\left\{S_{k}^{\mu}+S_{k}^{\phi}+S_{k}^{\xi}+(1+e) S_{k}^{\phi}\right\} \sum_{j=1}^{J} \frac{S_{j}^{\xi}}{1+e\left(S_{k}^{\mu}+S_{k}^{\phi}+S_{k}^{\xi}\right)} R_{j}^{\xi} G_{j}^{\xi} \\
& +\lim _{e \rightarrow \mathbf{0}} \frac{S_{k}^{\xi}}{1+e\left(S_{k}^{\mu}+S_{k}^{\phi}+S_{k}^{\xi}\right)+e(1+e) S_{k}^{\phi}} R_{k}^{\xi} G_{k}^{\xi} . \\
\lim _{e \rightarrow \mathbf{0}} \frac{G(e)-G}{e}=- & \left(S_{k}^{\mu}+2 S_{k}^{\phi}+S_{k}^{\xi}\right) G+S_{k}^{\mu} R_{k}^{\mu} G_{k}^{\mu}+2 S_{k}^{\phi} R_{k}^{\phi} G_{k}^{\phi}+S_{k}^{\xi} R_{k}^{\xi} G_{k}^{\xi} .
\end{aligned}
$$

It is straitforward to get (13) from (25). The proof for the extended Gini index is similar. 
Faculté des lettres et sciences humaines DÉPARTEMENT D'ÉONOMMUE

94-01 BILODEAU, Marc et AI SLIVINSKI, Toilet Cleaning and Department Chairing: Volunteering a Public Service.

94-02 ASCAH, Louis, Recent Retirement Income System Reform: Employer Plans, Public Plans and Tax Assisted Savings.

94-03 BILODEAU, M. et AI SLIVINSKI, Volunteering Nonprofit Entrepreneurial Services.

94-04 HANEL, Petr, R\&D, Inter-Industry and International Spillovers of Technology and the Total Factor Productivity Growth of Manufacturing Industries in Canada, 1974-1989.

94-05 KALULUMIA, Pene et Denis BOLDUC, Generalized Mixed Estimator for Nonlinear Models: A Maximum Likelihood Approach.

95-01 FORTIN, Mario et Patrice Langevin, L'efficacité du marché boursier face à la politique monétaire

95-02 HANEL, Petr et Patrice Kayembe YATSHIBI, Analyse de la performance à exporter des industries manufacturières du Québec 1988.

95-03 HANEL, Petr, The Czech Republic: Evolution and Structure of Foreign Trade in Industrial Goods in the Transition Period, 1989-1994.

95-04 KALULUMIA, Pene et Bernard DÉCALUWÉ, Surévaluation, ajustement et compétitivité externe : le cas des pays membres de la zone franc CFA.

95-05 LATULIPPE, Jean-Guy, Accès aux marchés des pays en développement.

96-01 ST-PIERRE, Alain et Petr HANEL, Les effets directs et indirects de l'activité de R\&D sur la profitabilité de la firme.

96-02 KALULUMIA, Pene et Alain MBAYA LUKUSA, Impact of budget deficits and international capital flows on money demand: Evidence From Cointegration and Error-Correction Model.

96-03 KALULUMIA, Pene et Pierre YOUROUGOU, Money and Income Causality In Developing Economies: $\boldsymbol{A}$ Case Study Of Selected Countries In Sub-Saharan Africa.

96-04 PARENT, Daniel, Survol des contributions théoriques et empiriques liées au capital humain (A Survey of Theoretical and Empirical Contributions to Human Capital).

96-05 PARENT, Daniel, Matching Human Capital and the Covariance Structure of Earnings.

96-06 PARENT, Daniel, Wages and Mobility : The Impact of Employer-Provided Training

97-01 PARENT, Daniel, Industry-Specific Capital and the Wage Profile : Evidence From the NLSY and the PSID.

97-02 PARENT, Daniel, Methods of Pay and Earnings: A Longitudinal Analysis.

97-03 PARENT, Daniel, Job Characteristics and the Form of Compensation.

97-04 FORTIN, Mario et Michel BERGERON, Jocelyn DUFORT et Pene KALULUMIA, Measuring The Impact of Swaps on the Interest Rate Risk of Financial Intermediaries Using Accounting Data. 
97-05 FORTIN, Mario, André LECLERC et Claude THIVIERGE, Testing For Scale and Scope Effects in Cooperative Banks: The Case of Les Caisses populaires et d'économie Desjardins.

97-06 HANEL, Petr, The Pros and Cons of Central and Eastern Europe Joining the EU

00-01 MAKDISSI, Paul et Jean-Yves DUCLOS, Restricted and Unrestricted Dominance Welfare, Inequality and Poverty Orderings

00-02 HANEL, Petr, John BALDWIN et David SABOURIN, Les déterminants des activités d'innovation dans les entreprises de fabrication canadiennes : le rôle des droits de propriété intellectuelle

00-03 KALULUMIA, Pene, Government Debt, Interest Rates and International Capital Flows: Evidence From Cointegration

00-04 MAKDISSI, Paul et Cyril TÉJÉDO, Problèmes d'appariement et politique de l'emploi

00-05 MAKDISSI, Paul et Quentin WODON, Consumption Dominance Curves: Testing for the Impact of Tax Reforms on Poverty.

00-06 FORTIN, Mario et André LECLERC, Demographic Changes and Real Housing Prices in Canada.

00-07 HANEL, Petr et Sofiene ZORGATI, Technology Spillovers and Trade: Empirical Evidence for the G7 Industrial Countries.

01-01 MAKDISSI, Paul et Quentin WODON, Migration, poverty, and housing: welfare comparisons using sequential stochastic dominance. Avril 2001, 23 p.

01-02 HUNG Nguyen Manh et Paul MAKDISSI, Infantile mortality and fertility decisions in a stochastic environment. Mars 2001, $12 \mathrm{p}$.

01-03 MAKDISSI, Paul et Quentin WODON, Fuel poverty and access to electricity: comparing households when they differ in needs. Juin 2001, $19 \mathrm{p}$.

01-04 MAKDISSI, Paul et Yves GROLEAU, Que pouvons-nous apprendre des profils de pauvreté canadiens ? Juillet 2001, $47 \mathrm{p}$.

01-05 MAKDISSI, Paul et Quentin WODON, Measuring poverty reduction and targeting performance under multiple government programs. Août 2001, $16 \mathrm{p}$.

01-06 DUCLOS, Jean-Yves et Paul MAKDISSI, Restricted inequality and relative poverty. Août 2001, $31 \mathrm{p}$.

01-07 TÉJÉDO, Cyril et Michel TRUCHON, Serial cost sharing in multidimensional contexts. Septembre 2001, $37 \mathrm{p}$.

01-08 TÉJÉDO, Cyril, Strategic analysis of the serial cost sharing rule with symmetric cost function. Février 2001, 25 p.

01-09 HANEL, Petr, Current intellectual protection practices by manufacturing firms in Canada. Septembre 2001, $57 \mathrm{p}$.

02-01 DUCLOS, Jean-Yves, Paul MAKDISSI et Quentin WODON, Socially-efficient tax reforms, Janvier 2002, $47 \mathrm{p}$.

02-02 MAKDISSI, Paul, La décroissance démographique : Pourquoi pas?, Février 2002, 20 p.

02-03 LECLERC, André et Mario FORTIN, Production et rationalisation des intermédiaires financiers : leçons à tirer de l'expérience des caisses populaires acadiennes Février 2002, 24 p.

02-04 HANEL, Petr et Snezana VUCIC, L'impact économique des activités de recherche de l'Université de Sherbrooke, Février 2002, $44 \mathrm{p}$.

02-05 TÉJÉDO, Cyril et Michel TRUCHON, Monotonicity and bounds for cost shares under the path serial rule, Mars 2002, $18 \mathrm{p}$. 
02-06 PORET, Sylvaine et Cyril TÉJÉDO, Analyse horizontale du marché des biens illicites, Mai 2002,15 p.

02-07 KALULUMIA, Pene, Effects of government debt on interest rates: evidence from causality tests in Johansen-type models, Juillet 2002, 21 p.

02-08 MAKDISSI, Paul et Quentin WODON, Can safety nets offset the impact of risk on wage inequality and social welfare? Août 2002, 12 p.

02-09 DUCLOS, Jean-Yves, Paul MAKDISSI et Quentin WODON, Poverty-reducing tax reforms with heterogeneous agents, Février 2002, $10 \mathrm{p}$.

02-10 MAKDISSI, Paul et Quentin WODON, Fuzzy targeting indices and orderings, Mai 2002, 11 p.

02-11 DUCLOS, Jean-Yves, Paul MAKDISSI et Quentin WODON, Poverty-efficient transfer programs : the role of targeting and allocation rules, Mai 2002, $25 \mathrm{p}$.

02-12 MAKDISSI, Paul et Quentin WODON, Environmental regulation and economic growth under education externalities, Août 2002, 8 p.

02-13 CHARTRAND, Frédéric et Mario FORTIN, L'impact du régime d'accession à la propriété sur la demande de logement, Novembre 2002, $46 \mathrm{p}$.

03-01 MAKDISSI, Paul et Quentin WODON, Gini decomposition and gini income elasticity under income variability, Avril 2003, 11p.

03-02 MAKDISSI, Paul et Quentin WODON, Robust comparisons of natural resources depletion indices, Avril 2003, $11 \mathrm{p}$.

03-03 MAKDISSI, Paul, Yannick THERRIEN et Quentin WODON, L'impact des transferts publics et des taxes sur la pauvreté au Canada et aux Etats-Unis, 28 p.

* Tous ces cahiers de recherche sont disponibles sur notre site WEB (www.usherbrooke.ca/economique) ou au Centre de documentation de la FLSH A3330 (Udes).

Prière d'adresser vos commentaires ou demandes d'exemplaires d'un cahier de recherche antérieur (1976 à 1990) à monsieur Cyril TÉJÉDO, responsable des Cahiers de recherche du Département d'économique, Tél : (819) 821-7233 Télécopieur : (819) 821-7237 Courriel : Cyril.Tejedo@USherbrooke.ca

Comments or requests for copięs of previous Working Papers (1976 to 1990) should be made to the Research Papers Supervisor at the "Département d'économique ", Mr. Cyril TÉDÉDO. Tel: (819) 821-7233 FAX:819) 821-7237 E-mail: Cyril.Tejedo@USherbrooke.ca.

Révisé le 28 avril 2003 